\title{
As alternativas de construção de "um outro mundo possível": Movimentos Sociais, Estado e/ou Classe Trabalhadora?
}

\author{
The building alternatives: \\ “another possible world”. Social Movements, State and/or \\ Working Class?
}

\author{
Wolney Roberto Carvalho \\ Doutor em Sociologia Política pela Universidade Federal de Santa Catarina (UFSC) \\ Professor da Universidade Federal da Integração Latino-Americana (UNILA) \\ wolneyc@hotmail.com \\ Samya Campana \\ Doutoranda em Educação pela Universidade Federal de Santa Catarina (UFSC) \\ samyacampana@gmail.com
}

\begin{abstract}
Resumo: Considerando que o modo de produção capitalista é o produtor da desigualdade social e insuficiente como garantidor das condições elementares humanas, o artigo tem como objetivo apresentar as alternativas para a construção de 'um outro mundo possível', lançando mão da abordagem de Immanuel Wallerstein e Ellen Wood para elucidar a importância da participação dos movimentos sociais, do Estado e da classe trabalhadora no processo. Para tanto, o artigo propõe um diálogo crítico, especialmente acerca da posição assumida por Wallerstein, a partir de uma breve exposição acerca da formulação de ambos os autores sobre o assunto e em se tratando da crise atual do capitalismo. $O$ resultado dessa investigação aponta que as possibilidades efetivas de "um outro mundo" encontram respaldo na atuação da classe trabalhadora no poder do Estado.
\end{abstract}

Palavras-chave: Movimentos Sociais. Estado. Classe Trabalhadora.

\begin{abstract}
Considering that the capitalist production way is the social inequality producer and inefficient as assurer of human elementary conditions. Thus, the paper aims to present the alternatives for building "another possible world", taking Immanuel Wallerstein e Ellen Wood as an approach to elucidate the importance of the social movement, State and working class participations in the process. Therefore, the paper proposes a critical dialogue, especially, about what Wallerstein states from a brief report of both authors about the subject and the current capitalism crisis. The result of this investigation points out that the effective possibilities of "another world" are supported by the working class actions on the State power.
\end{abstract}

Keywords: Social Movements. State. Working Class.

Originais recebidos em: 27/06/2013

Aceito para publicação em: 29/08/2013

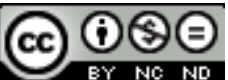

Este trabalho está licenciado sob uma Licença Creative Commons Atribuição-Uso NãoComercial-Vedada a criação de obras derivadas 3.0 Unported License. 


\section{Prolegômenos sobre o mundo moderno: Estado de direito, liberalismo político-econômico}

O homem moderno em suas relações sociais tem sido analisado de várias maneiras e, a partir dessas relações, é que se abrem as possibilidades para a efetivação de uma sociedade onde a produção da vida possa aparecer como objetivo maior.

No entanto, compreender que a produção da vida pode ser efetivada requer sempre uma análise de como esse homem produz a sua existência.

Assim, pode-se constatar inicialmente que esse homem aparece como livre para ir e vir, liberto do mundo feudal, da tradição, da hierarquização divina e com igualdades nas relações jurídicas para com os seus semelhantes, bem como - através dos princípios democráticos oriundos do liberalismo - com o direito de escolher seus representantes na esfera do político.

Essa nova sociedade e esse novo homem estão assentados sobre relações sociais de produção de novo tipo, que vêm acompanhadas de um novo tipo de Estado (ente político) e de novas normas sociais que se expressam em novos conhecimentos jurídicos. Surge, assim, da degeneração do mundo feudal, um novo mundo que vai concretizando-se e impondo-se não somente por relações econômicas e sociais, mas jurídicas, expressadas pelo Estado e o Direito modernos.

Comumente, esse mundo moderno é chamado de capitalismo, ora com o intuito de referenciar as relações econômicas de produção, sociais e jurídicas de novo tipo, ora com a intenção de destacar que o homem que, ao se desencantar com o mundo feudal, assume uma racionalidade, uma cientificidade que o conduzirá ao bem estar social.

Porque, até então, as idealizações de um "mundo melhor", por exemplo, por meio de Thomas More (1478 - 1535), com sua Utopia, Francis Bacon (1561 - 1626), com a Nova Atlântida e Tommaso Campanhella (1568 - 1639), com a Cidade do Sol, eram apenas construções do imaginário, no sentido de que não se embasavam em experimentos reais, não eram empiricamente verificáveis e socialmente postos para todos os homens. Não obstante, para além de serem construções do imaginário, "o que havia de comum nesses lugares utópicos, é que neles o trabalho organizava a vida das pessoas" (GRADE, 2006, p. 16), como de fato o era.

A partir desse momento histórico - e isso remonta ao final dos séculos XVII e início do século XVIII - é que se estabelecem as discussões científicas acerca da emancipação humana, da constituição de uma sociedade com uma estrutura social na 
qual todas as pessoas teriam suas tarefas e seu espaço específico, possibilitando a todos os homens a reprodução de sua existência em condições de igualdade e liberdade, principalmente econômica e política. O homem moderno, de novo tipo, pelo trabalho, não só almejava, mas lutava empiricamente para ser livre/emancipado econômica, política e socialmente em relação às amarras feudais, religiosas e monárquicas que o determinavam. Economicamente, a lei válida era a lei do valor, da troca de equivalentes.

No entanto, de acordo com Belluzzo (1997), a economia política clássica constata, amparada nos pressupostos filosóficos do liberalismo clássico e após "abandonar a discussão do trabalho como sendo o cerne da produção da riqueza material”, que os homens devem buscar a utilidade máxima nos seus afazeres, no consumo de seus bens, e seguir os pressupostos econômicos da lei da oferta e demanda, deixando à mão invisível do mercado a melhor alocação dos fatores de produção: terra, capital e trabalho.

Dessa maneira, segundo Belluzzo (1997), Adam Smith (1723 - 1790) destacará que todo o bem estar do homem moderno se manifestará de acordo com a maximização desses fatores de produção, que em última instância são a fonte originária de toda a riqueza, de todo valor produzido. David Ricardo (1772 - 1823), por sua vez, aprofundando os apontamentos de A. Smith, constatará que o crescimento econômico deverá sempre ser perseguido para que o bem estar social aumente e, nesse sentido, defenderá - com uma postura ideológica definida - a classe capitalista industrial inglesa como a protagonista da história para a emancipação humana.

Entretanto, se os indivíduos são econômica e juridicamente livres e iguais, constituirão o que se chama de sociedade civil, a qual é regulada pelo Estado. Veja-se que para garantir a livre iniciativa, o bom funcionamento dos mercados, o respeito às normas e à ordem social, assim como o respeito à propriedade dos fatores de produção, este ente regulador se valerá do direito moderno.

Belluzzo (1997) destaca que o Estado teoricamente assumirá a função reguladora e interventora no mercado, quando - em casos excepcionais - a iniciativa privada, sob a proteção da mão invisível do mercado, não tiver competência para criar as condições necessárias ao seu bom funcionamento.

É importante destacar que esses princípios da economia clássica e do liberalismo clássico ratificam-se com a Revolução Francesa e se espraiam pelo mundo. Assim, pode-se dizer que a emancipação humana é apresentada como resultado final da 
ampliação desses princípios no âmbito da produção social, os quais são a base científica do modo de produção capitalista.

No entanto, os princípios políticos e econômicos do capitalismo foram capazes de garantir a democracia ao homem moderno? Conduzem de fato à emancipação humana? Garantem os chamados Direitos Humanos elementares?

Uma análise mais aprofundada nos mostrará que essa crença no progresso econômico capitalista, não confirma a esperança desejada pela humanidade.

\section{Breve exposição da posição de Immanuel Wallerstein e Ellen Wood: limitação do capitalismo e alternativas}

Para Wallerstein (2001), a partir do século XVI teve início uma economia mundo capitalista, ou que ele denomina de sistema histórico capitalista. Esse sistema nasce amparado no antagonismo de classes, capitalistas versus trabalhadores, que se apresenta nas relações sociais de produção. Essas, dão origem às cadeias mercantis que, a partir da divisão social do trabalho, se apresentam espacialmente estruturadas em regiões centrais, semi-periféricas e periferias.

Assim, com a expansão da economia-mundo capitalista, expandem-se com ela as cadeias mercantis e o sistema histórico capitalista que se estrutura num formato orgânico de circulação dos fluxos produtivos e financeiros entre as regiões.

Constata Wallerstein (1999) que é praticamente impossível individualmente um país ou mesmo uma determinada região se desenvolver economicamente, pois o que se desenvolve não são países ou regiões isoladamente, mas o conjunto da economia-mundo como um todo.

Isso implica que se as bases do sistema histórico capitalista se assentam na estrutura centro, semi-periferia e periferia, os fluxos econômicos produtivos e/ou financeiros estarão igualmente circunscritos à essa estrutura, e o que se verifica recentemente é uma crescente desindustrialização de determinados setores das economias centrais, os quais serão gradualmente transferidos para os países que fazem parte da semi-periferia e periferia.

Aos países centrais competem as atividades na esfera produtiva, financeira e de serviços elaboradas a partir de um alto grau de desenvolvimento tecnológico, com grandes ganhos de produtividade e competitividade, juntamente com a exigência de uma 
força de trabalho altamente qualificada e que não podem, em geral, ser encontradas nas outras regiões da estrutura do sistema histórico.

Por outro lado, as bases produtivas, financeiras e de serviços que poderão ser desenvolvidas a partir da exploração de uma força de trabalho menos qualificada são transferidas para as regiões semi-periféricas e periféricas, o que possibilita aos capitalistas uma redução nos custos da força de trabalho e com isso a manutenção ou o aumento das taxas de lucro.

É importante perceber que, apesar dessa estrutura orgânica da economia mundo capitalista, nas próprias regiões centrais também opera uma divisão social do trabalho no interior das cadeias mercantis. Assim, isso implicará, evidentemente, que em qualquer país do centro do sistema também haverá regiões semi-periféricas e periféricas, ainda que com impactos sociais menores.

Dado a natureza dessa estrutura - segundo Wallerstein (1999) -, o que se verifica é estabelecimento das trocas desiguais entre as regiões, o que possibilita que as regiões centrais do sistema histórico se apropriarem de parte do excedente econômico gerado na semi-periferia e na periferia.

Aparecem, assim, dois movimentos importantes operados pelos capitalistas. O primeiro se refere ao fato de que os capitalistas avaliam em todas as suas operações produtivas, financeiras e/ou de prestação de serviços os custos de transação e da força de trabalho. De olho nos custos-benefícios, quando os custos de transação são mais elevados que os custos da força de trabalho, deslocam seus centros produtivos e de serviços para regiões mais urbanizadas ou centrais, de fácil escoamento de mercadorias, transporte e de negociações - são as fases A do ciclo de Kondratiev. Nos momentos em que os custos da força de trabalho são mais elevados, o movimento em geral é inverso, ou seja, deslocam seus centros - em especial produtivos - para regiões mais semiperiféricas e (ou) periféricas - fases B do ciclo de Kondratiev. Note-se que, para Wallerstein (1999), esse movimento é efetuado há pelo menos 500 anos em todo o sistema histórico capitalista.

O segundo movimento importante é que simultaneamente às alianças estratégicas efetuadas na economia mundo capitalista - com o objetivo de aumentar os lucros - os capitalistas também competem entre si e, nessa competição, aqueles vinculados aos Estados-nação do centro do sistema se apropriam de parte do excedente acumulado pelos capitalistas das regiões semi-periféricas e periféricas. Aqui ressalta-se a importância do Estado-nação moderno no amparo aos seus capitalistas nacionais, 
todavia, percebe-se que os Estados centrais possuem maior poder de influência política, econômica e militar, os quais são indispensáveis para a reprodução do capital.

Nesse sentido, Wallerstein (1999) demonstra a limitação e a fraqueza dos Estados-nação da semi-periferia e periferia, pois essa estrutura orgânica se mantém praticamente imóvel ao longo da existência do capitalismo, ou seja, para um Estadonação se deslocar da condição periférica para semi-periférica, ou dessa para o centro, deverá haver um deslocamento inverso por parte de algum outro Estado-nação.

Será possível, para o autor acima, algum tipo de democracia nesse sistema histórico? Será possível a garantia dos Direitos Humanos elementares?

Wallerstein (2002) constata que, a partir do século XX, considerando as crises sociais que se apresentavam, se instalou um debate acerca da autodeterminação dos povos. Por um lado, Woodrow Wilson, representando o governo estadunidense e, por outro, os Bolcheviques, o governo da URSS, realizavam campanhas para uma participação efetiva no processo de independentização e maior participação política, focados na retórica do desenvolvimento econômico a partir de uma estratégia liberal e outra socialista.

Esse debate toma força após 1945, mas já nos anos 1960 mostra indícios de esgotamento. As doutrinas liberais dos EUA tinham perdido parte da sua força de propagação e, na Europa, o que havia se implantado era a social democracia, tendo na sua base um Estado keynesiano forte. Na Ásia, África e América-latina, a gestão do Estado se fundamenta em movimentos de libertação nacional e populistas.

No entanto, na esteira dos debates sobre reforma ou revolução, e passados 15 anos depois da Segunda Grande Guerra, os movimentos anti-sistêmicos (movimentos sociais e de libertação nacional) encontravam-se espalhados pela América Latina, África e Ásia, assim como em alguns países da Europa.

Se os vencedores foram os que entendiam que a estratégia era tomar o poder do Estado-nação, que o inimigo comum era o capitalismo, por outro lado, a etapa de transformação do mundo não chegou a se concretizar. Wallerstein (2005) destaca que, mesmo com uma simbiose nas estratégias dos movimentos socialistas e nacionalistas quando os intelectuais passaram a perceber a necessidade de atuarem junto às massas -, seus líderes, ao terem o poder em suas mãos, se defrontaram com a limitação para a transformação do mundo, o que se deve ao seguinte fato: aquilo que 
Estados estavam limitados pelo fato de fazerem parte de um sistema interestado, no qual nenhum membro possuía soberania absoluta. (WALLERSTEIN, 2005, p. 267).

Surgem novos movimentos sociais a partir dos anos 1960, os quais trazem críticas severas à hegemonia dos EUA, à conivência da URSS e aos tropeços da velha esquerda, em especial na periferia. Os esforços anti-sistêmicos de Cuba e Coréia em 1959, do Vietnã em 1968, juntamente com a revolução cultural na China e as greves gerais na França, demonstraram o esgotamento da proposta de emancipação humana através do liberalismo, ou seja, que o sistema histórico capitalista não poderia estender suas benesses a todos.

Nessa direção, os novos movimentos sociais pós 1960 - para Wallerstein (2005) - se alinham com a massa e trazem consigo a descrença de mudanças através da tomada do poder do Estado. Os maoístas acreditavam que se deveria recuperar as estratégias revolucionárias pautadas na revolução cultural chinesa; os verdes e ecológicos (que compunham a New Left no anos 1970) entendiam que as minorias, as mulheres e o meio-ambiente deveriam ser incluídos nas discussões para uma efetiva transformação social; e, nos anos 1980, surgem as organizações pelos Direitos Humanos que, pouco a pouco, se transformam em $\mathrm{ONG}^{\prime} \mathrm{S}$, em muitos casos, apologetas dos Estados nacionais.

Assim, para Wallerstein (2005), a crítica norteadora desses novos movimentos sociais foi a de que o controle do poder do Estado, no Centro, semi-periferia ou na periferia - ainda que assumindo uma proposta social-democrata, populista, de libertação nacional ou mesmo comunista - esteve muito atrelado à grupos privilegiados, não sendo possível apresentar perspectivas de inclusão social de forma a ratificar uma transformação social efetiva. Isso por sua vez, conduziu à descrença total nos políticos e nos Estados nacionais.

No entanto, se esses movimentos sociais surgidos entre os anos 1960 e 1980 não foram tão bem sucedidos como o esperado, isso se concretizará - na visão do referido autor -, a partir de 2001, no Fórum Social Mundial (FSM) em Porto Alegre, Brasil.

Assim, o Fórum teve a grandiosidade de reunir todos os movimentos antisistêmicos (locais, regionais, nacionais e transnacionais) com o slogan "Um outro mundo é possível", contrapondo-se às doutrinas neoliberais (liberdade de movimento de capitais, de bens e serviços, forte atuação do Congresso de Washington, FMI e Banco Mundial). 
Todavia, deve ser observado na atualidade - segundo o respectivo autor - que o sistema histórico capitalista passa por um era de transição, de bifurcação sistêmica, o que poderá resultar em caos sistêmico ou na construção de um novo sistema histórico.

Quanto ao caos sistêmico, esse poderá conduzir à extinção de parte da humanidade, inclusive da riqueza material existente; quanto ao novo sistema histórico, este poderá surgir em uma nova estrutura hierárquica e de privilégios, ou mesmo, em uma estrutura mais igualitária, de inclusão social, a exemplo da garantia dos direitos humanos elementares (educação, saúde, alimentação, habitação).

Nesse sentido, de acordo com Wallerstein (2005), nada está garantido, pois quem está no poder - os grandes capitalistas, tradicionalistas e falcões militares - sabe que o sistema histórico capitalista está se desintegrando, que já se encontra em uma fase de transição para um novo sistema histórico e, mediante isso, fará tudo que for necessário para manter as estruturas de poder.

Portanto, aos movimentos sociais articulados em torno do FSM resta a discussão de um sistema histórico que garanta os direitos humanos elementares, bem como, a ampliação das bases democráticas, pois como se demonstrou, isso não é prioridade no sistema histórico capitalista, em especial, porque, sua estrutura orgânica se fundamenta na busca incessante pelo lucro em todos os espaços geográficos. Faz-se necessário segundo o autor: a) debater ampla e abertamente a transição e os resultados que esperamos; b) não abandonar a ação eleitoral no curto prazo; c) no médio prazo, buscar a desmercantilização e a sobrevivência de algumas empresas, sem visar o lucro; d) no longo prazo, buscar a democracia e a igualdade.

Contudo, se, para Wallerstein (2005), os movimentos sociais assumem a primazia no processo de transição e englobam todos os esforços anti-sistêmicos dos mais variados atores sociais, para Wood (2005), o esforço da transição para a construção de "um outro mundo possível" está na luta de classes que se estabelece no seio do Estado.

Buscando compreender as perspectivas revolucionárias, Wood (2005) faz uma análise da globalização e seus efeitos sobre os Estados nacionais. Constata através do instrumental teórico marxista, que a globalização não é um fenômeno recente, "mas um processo de longo prazo; não se trata de um novo tipo de capitalismo, mas de lógica do capitalismo tal como este foi desde o começo" (p. 101). 
Dessa maneira, se a globalização não é um fenômeno novo no capitalismo, mas tem se intensificado, o que se verifica é um aumento da competição entre capitalistas pela apropriação do produto excedente.

O processo de centralização dos capitais - para Wood (2005) - está cada vez mais amparado na competição capitalista e se nos principais setores econômicos a reprodução do capital vai se estruturando a partir de alguns monopólios e muitos oligopólios, esses exercem uma grande competição pela apropriação da mais-valia, tanto no plano nacional como no internacional.

Será que na atualidade o predomínio é de grandes empresas multinacionais, as quais conseguem deslocar seus parques produtivos - como sugere Wallerstein -, de acordo com as alterações nos custos de transação e nos custos da força de trabalho? Constata-se em Wood (2005) que isso não é possível para a grande maioria das empresas, pois quando destinam o capital acumulado em um processo de reprodução do capital, alocando boa parcela de seu recurso na compra dos meios de produção instalações físicas e máquinas -, o fazem visando o longo prazo. Isso por sua vez, implicará na enorme dificuldade de reconversão desses meios de produção em capitaldinheiro, ou seja, na venda do parque produtivo. Ademais, adiciona-se a inviabilidade do deslocamento desses meios de produção para outra espacialização geográfica.

Portanto, com o desenvolvimento do modo de produção capitalista e a expansão da globalização, para além da concentração dos capitais, se verifica o acirramento da competição entre as grandes empresas, o que conduz à crescente centralização dos capitais - em geral, oligopólios e (ou) monopólios nacionais e (ou) internacionais. E esse movimento é acompanhado por um ator importante sem o qual o capitalismo não poderia existir: o Estado nacional, sempre importante nos países centrais e periféricos.

A atuação do Estado se faz relevante tanto para os oligopólios e monopólios que atuam no mercado nacional, quanto para os que atuam no mercado mundial, ou mesmo para essas grandes empresas que atuam em ambos. No primeiro caso, a atuação do Estado nacional é primordial na criação da infraestrutura necessária para o processo de reprodução do capital. Aliado a isso, as grandes subvenções e subsídios concedidos aos oligopólios e monopólios se traduzem em importantes estímulos para a acumulação do capital. Também é extremamente necessário que o ente político estabeleça as condições jurídicas e institucionais de amparo e assistência social, buscando criar as condições necessárias para viabilizar uma força de trabalho sempre apta às necessidades de acumulação do capital. 
No segundo caso, isto é, considerando-se as grandes empresas de determinado país que atuam no mercado mundial, cabe ao Estado nacional efetuar as negociações interestatais necessárias para a garantia da propriedade privada dessas empresas, dos espaços de acumulação de capital e em muitos casos até da criação de uma força de trabalho qualificada para tal, utilizando quando necessário inclusive a militarização.

Portanto, se para uma parte da esquerda ocidental, a tarefa e a responsabilidade histórica na busca pelo socialismo ou de um "outro mundo..." fica ao cargo da intelectualidade como vanguarda buscando-se a tomada do poder de Estado, ou - como defende Wallerstein - dos movimentos sociais, para Wood (2005), essa tarefa continua sendo da classe trabalhadora.

Contudo, a classe trabalhadora está confinada à produção da riqueza material em unidades produtivas distintas, locus por excelência da produção da mais-valia, (ou mesmo em unidades responsáveis pela circulação do capital distintas), e isso implica segundo Wood (2005) - simultaneamente que a luta de classe apresenta uma tendência à descentralização, inclusive porque, muitas vezes, os trabalhadores de determinado setor econômico acabam por aliarem-se aos capitalistas na luta concorrencial, visando à manutenção de seus empregos. Todavia, isso:

não é produto de uma falha na consciência de classe dos trabalhadores. É
uma resposta a uma realidade material, à forma como o mundo social é
realmente organizado pelo capitalismo. É necessário acrescentar aqui que,
apesar de os conflitos de classe estarem localizados dessa maneira, a classe
trabalhadora está ainda mais dividida pela competição entre as empresa, na
qual os trabalhadores são levados a se ver como aliados de seus exploradores
contra seus competidores, tanto capitalistas como trabalhadores. Essa é uma
tendência que a ideologia da globalização está tratando de promover em
todos os meios (WOOD, 2005, p. 108).

Sendo assim, qual deverá ser o espaço para a centralização dos objetivos da classe trabalhadora na busca pela democracia, pelos Direitos Humanos elementares e pela construção de um "outro mundo possível"? Como se demonstrou, o modo de produção capitalista é excludente e não possibilita o cumprimento desses requisitos. Wood (2005) acredita que esse espaço diz respeito à esfera do Estado nacional, pois esse é o principal agente da globalização e que, inclusive, participa da concorrência capitalista juntamente com as grandes empresas. Além disso, o Estado não somente cumpre os requisitos da dinâmica da acumulação capitalista, mas é conivente com essa dinâmica, ao mesmo tempo em que contém os conflitos de classes gerados em seu interior.

Conforme o exposto, a luta de classes deverá se dirigir para o Estado, pois: 
se o Estado é o canal através do qual o capital se move na economia globalizada, então é igualmente o meio pelo qual uma força anticapitalista poderia cortar pela raiz esse tipo de vida capitalista....Mas o que isso significa é que a ação política já não pode simplesmente assumir a forma de intervir na economia capitalista. Agora se trata de separar a vida material da lógica do capitalismo. (WOOD, 2005, p. 113).

A ação política deve primar pela utilização do poder do Estado nacional - de acordo com Wood (2005) -, visando controlar os movimentos de capitais, bem como, a destinação do superávit econômico para uma lógica social diferente da capitalista.

Essa estratégia deve ser efetuada através da classe trabalhadora, organizada em movimentos locais e nacionais na luta contra o capitalismo nacional, objetivando o poder do Estado nacional. A partir daí, do cumprimento da tarefa de casa, será possível a construção de um novo internacionalismo.

\section{Considerações finais}

Como se viu, na tentativa de entender a modernidade, o homem moderno em suas relações sociais e as possibilidades de sua emancipação, a partir de Wallerstein e Wood, há divergências entre ambos.

Pode-se dizer que Adam Smith e David Ricardo acreditaram que o capitalismo se apresentava como o "fim da história", e a emancipação humana, entendido por direitos humanos elementares, a democracia e a materialidade, seriam estendidos à todos com a universalização da liberdade para ir e vir, a igualdade jurídica, a livre iniciativa. A lei da oferta e demanda deveria prevalecer sob a proteção da mão invisível do mercado. Isso possibilitaria o crescimento econômico e, a tarefa maior, a distribuição da riqueza produzida de acordo com os respectivos fatores de produção: terra (renda da terra), capital (lucro e juros) e trabalho (salários). Inevitavelmente, o bem estar geral da sociedade seria alcançado, uma vez que se respeitassem essas leis naturais.

Wallerstein, discordando da possibilidade dos princípios econômico-filosóficos adotados pela economia política clássica, compreende o capitalismo enquanto um Sistema Histórico que traz em seu seio o antagonismo de classes, a separação entre proprietários e não-proprietários do capital. Mas essa economia mundo capitalista, estruturada a partir de cadeias mercantis - que trazem em seu seio a divisão social do trabalho -, conduz o sistema histórico a uma estrutura orgânica e sistêmica, denominada por ele de centro, semi-periferia e periferia. Assim, em especial a partir do século XIX, todas as regiões do mundo inserem-se nessa estrutura orgânica. 
A dinâmica da reprodução do capital se aloca de acordo com essa estrutura e, simultaneamente, é dela dependente. No centro do sistema encontram-se os processos produtivos, comerciais e financeiros tecnologicamente mais avançados, os grandes laboratórios científicos, os Estados-nação política, econômica e militarmente fortes. Aí também se encontram as grandes empresas ou suas matrizes - empresas multinacionais -, detentoras de capitais gigantescos e que operam por toda a economia mundo. Finalmente, a parcela da força de trabalho mais qualificada também se faz presente nessas regiões.

Assim sendo, com o objetivo máximo do lucro, essas grandes empresas atuam em todo o sistema histórico na busca pela acumulação de capital.

Nas regiões semi-periféricas e periféricas, encontram-se os processos produtivos, comerciais e financeiros tecnologicamente menos avançados, laboratórios científicos de menor estrutura, expressão de Estados-nação com estrutura política, econômica e militar mais débil. Também se encontram grandes empresas nessas regiões, mas em menor número e, geralmente propriedade de residentes no país associados à estrangeiros do centro do sistema. Note-se que essas empresas, assim como em toda economia-mundo, operam nos principais setores econômicos. A força de trabalho nessas regiões é menos qualificada que a força de trabalho nas regiões centrais e, em muitas partes, se enquadra numa estrutura semi-proletária - onde parte da família produz a própria subsistência.

Como a dinâmica da acumulação de capital se dá ao longo de toda economia mundo e, a competição cada vez mais acirrada nos principais setores econômicos inclusive mundialmente -, exige a participação de um Estado-nação igualmente competitivo, cada vez mais próximo dos grandes capitalistas nacionais e do jogo capitalista mundial.

No entanto, se o Estado-nação está cada vez mais nas mãos dos capitalistas, a estrutura mundial os Estados-nação semi-periféricos e periféricos perderam boa parte de sua soberania para os Estados centrais.

Assim sendo, para Wallerstein, os movimentos sociais perderam a crença nos Estados nacionais, pois estes se tornaram reféns dos capitalistas. Nesse sentido, qualquer proposta ideológica de inclusão social e garantia dos direitos humanos elementares não se ratifica. Ademais, se o que se desenvolve é a economia-mundo como um todo, e há uma hierarquia no sistema interestado, a luta anti-sistêmica deverá ser articulada globalmente. Eis, assim, a importância do Fórum Social Mundial, na medida 
em que este consegue reunir todos os movimentos sociais que adotam uma postura antisistêmica.

Contudo, se Wallerstein propõe a construção de um novo sistema histórico apostando nos movimentos sociais, entende-se que este considera menos importante em suas análises, que o capitalismo é um Modo de Produção assentado em relações sociais de produção, locus de um conflito permanente entre os que produzem a riqueza material e os que se apropriam dela sem nada dar em contrapartida, isto é, entre os trabalhadores e os capitalistas. Ademais, a importância da dialética existente entre a estrutura e a superestrutura do modo de produção capitalista, bem como as múltiplas determinações que a partir daí se desenvolvem, ao que tudo indica, são relegadas para um segundo plano.

Portanto, se Wallerstein não considera a classe trabalhadora como sujeito da história- mas sim os movimentos sociais -, não é possível a concepção de um novo sistema histórico baseado em uma nova forma de organização social da produção material.

Finalmente, por não compreender os Estados nacionais (a superestrutura) como espaços onde a contradição entre capitalistas e trabalhadores se apresenta mais concentrada e, com maior força, só pode conceber uma mudança no sistema histórico a partir de movimentos sociais, que reivindicam outro "mundo possível" a partir dos reclames de injustiças, exclusão social, destruição do meio-ambiente, racismo etc.

Isso não deixa de ser relevante, contudo, sem a percepção de como a emancipação do homem moderno, a democracia e a garantia dos direitos humanos elementares vinculam-se ao modo como os homens produzem a sua existência material, de como os homens produzem a riqueza social, certamente os capitalistas levarão vantagem.

Essa é a diferença da abordagem de Wood. Longe de negar o esgotamento do capitalismo, compreende-o como um modo de produção que se fundamenta em relações sociais de produção originadas do antagonismo entre trabalhadores e capitalistas.

Os primeiros, responsáveis pela produção da riqueza material, cada vez mais são distanciados dos produtos de seus próprios trabalhos. A democracia e a garantia dos direitos humanos elementares (alimentação, saúde, educação, habitação) tornam-se distantes com o passar das décadas e mostram que o modo de produção capitalista é excludente. 
Os segundos, cada vez mais se apropriam da riqueza social produzida, centralizam gigantescas somas do produto excedente, da mais-valia, explorando cada vez mais os trabalhadores que ainda se encontram empregados.

Se no bojo do desenvolvimento desse modo de produção, a concorrência e o crédito são as mais poderosas alavancas da centralização e acumulação capitalista, isso não poderá se concretizar sem a enorme ajuda do Estado capitalista. Esse Estado capitalista tem o poder de ser conivente com os capitalistas, de criar toda a infraestrutura necessária para a reprodução do capital. E mais do que isso, na atualidade, concentra em média, pelo menos, $35 \%$ do produto excedente criado pelos trabalhadores, pois donde provêm os recursos do Estado? Como sabemos, o grosso dos recursos do Estado provêm de impostos, taxas e tributos cobrados das empresas e dos trabalhadores. Já é possível perceber porque os capitalistas se apropriam do Estado. Porém, de onde provêm esses recursos destinados pelas empresas para o Estado?

Como se demonstrou ao longo dessa discussão, e com base em Wood, a classe trabalhadora é a única e verdadeira produtora da riqueza material social. Ocorre que o trabalhador, ao vender a sua força de trabalho, dá ao capitalista o direito de se apropriar do trabalho excedente criado por essa força de trabalho, que nada mais é que a maisvalia. Essa mais-valia aparece na forma de lucro, juros, aluguéis ou renda da terra, mas quando o capitalista paga os impostos, taxas e tributos ao Estado, o que faz ele? Diminui parte do seu lucro, destinando-a para o Estado. Portanto, a principal fonte de receita do Estado moderno é parte da mais-valia apropriada pelo capitalista ao longo do processo de reprodução do capital.

Conclui-se, assim, que não há dúvidas que o Estado moderno deve se constituir no espaço de luta da classe trabalhadora. É aí que o produto excedente, produzido pelo trabalhador coletivo se encontra mais centralizado. E, sabendo-se das múltiplas determinações entre a estrutura e a superestrutura no modo de produção capitalista, entende-se que a busca de uma nova forma de organização social da produção deverá partir do que há de mais avançado em termos de organização social da produção no modo de produção capitalista, extrair a positividade das contradições que ali se manifestam para a classe trabalhadora e, a parti daí, atuando historicamente, construir o “outro mundo possível”. Porém, esse “outro mundo possível” somente poderá se concretizar, no momento em que o trabalhador coletivo tiver à sua disposição, os recursos materiais para construí-lo. Por isso o Estado como foco. 
Finalmente, um exemplo: sabe-se que no formato da reprodução do capital que se apresenta sob as grandes sociedades anônimas, o processo de reprodução do capital, em termos da criação da riqueza e da apropriação dessa riqueza, se apresenta como forma mais avançada. Como poderá o trabalhador coletivo ser criador da riqueza material e o proprietário dela a partir desse formato? A primeira pergunta que se faz necessário é: terá o trabalhador coletivo os meios materiais necessários para iniciar essa experiência histórica? Conclui-se que isso só poderá ser possível a partir da classe trabalhadora no poder do Estado.

\section{Bibliografia}

BELLUZZO, G. M. Luiz. Valor e capitalismo. Campinas: Instituto de Economia/ UNICAMP. 1987.

GRADE, Marlene. Fórum do Maciço do Morro da Cruz e Agreco como espaço transitório: germinando a espacialização de relações solidária em Santa Catarina. Tese de Doutorado em Geografia - Programa de Pós-graduação em Geografia, Universidade Federal de Santa Catarina.

RICARDO, David. Princípios de Economia Política e Tributação. São Paulo: Abril, 1983.

SMITH, Adam. A riqueza das Nações: Investigação sobre sua Natureza e suas causas. São Paulo: Abril, 1983

WALLERSTEIN, Immanuel. Após o liberalismo. Em busca da reconstrução do mundo. Petrópolis, RJ: Vozes, 2002. 2001.

Capitalismo histórico e civilização capitalista. Rio de Janeiro: Contraponto,

“A reestruturação capitalista e o sistema-mundo". In:GENTILLI, Pablo (Org.). Globalização excludente. Petrópolis, RJ: Vozes, 1999.

"O que significa hoje ser um movimento anti-sistêmico". In: LEHER, Roberto \& SETÚBAL, Mariana (Org.). Pensamento crítico e movimentos sociais: diálogos para uma nova práxis. São Paulo: Cortez, 2005.

WOOD, M. Ellen. "Trabalho, classe e Estado no capitalismo global”, In: LEHER, Roberto \& SETÚBAL, Mariana (Org.). Pensamento crítico e movimentos sociais: diálogos para uma nova práxis. São Paulo: Cortez, 2005. 